\title{
Rail transport- rail safety from a human risk point of view
}

\author{
Rafal Burdzik ${ }^{1}$, Pawel Słowiński ${ }^{2}$, Jacek Rozmus ${ }^{3}$, Bogusław Nowak ${ }^{4}$ \\ ${ }^{1,2}$ Silesian University of Technology, Faculty of Transport, 40-019, Katowice, Poland \\ ${ }^{3,4}$ DR-TECH Sp. z. o.o., 41-407 Imielin, Poland \\ ${ }^{1}$ Corresponding author \\ E-mail: ${ }^{1}$ rafal.burdzik@polsl.pl, ${ }^{2}$ pawel.slowinski@polsl.pl, ${ }^{3}$ jacek@drtech.pl, ${ }^{4}$ boguslaw@drtech.pl
}

Received 11 September 2017; accepted 13 September 2017

DOI https://doi.org/10.21595/vp.2017.19107

Check for updates

\begin{abstract}
This article aims are presenting the hazards arising from the direct contact of people with moving rail vehicles as well as the safety and consequence of human contact with the drag caused by the railroad system. This is the review paper with intended to illustrate and further analyze the risks, as well as to identify ways to identify such risks so that they can be counteracted.
\end{abstract}

Keywords: rail vibration, RAMS, railroad safety.

\section{Introduction}

Nowadays an important factor in choosing a location for new housing and the development of urban agglomerations is comfort in a broad sense of the word. Focusing on the aspect of transport and comfort factors, we can distinguish two significant factors for choosing the right locations for this type of venture. The first factor is access to public transport and the other is the impact of noise and vibration on the environment including the human. Concentrating on rail transport which has lost popularity in the last two decades, which is less popular than a few decades ago but it is still a popular means of transportation, especially as an alternative, complementary of urban, intercity and transport of goods of considerable cubature. The trend that is increasingly important in these times is the increase in speed and weight of rail trains [1-4]. These factors have a direct impact on the comfort of people living near railways. Another important factor is the health of passengers, drivers and people in direct contact with moving rail vehicles. Caring for railroad employees and passengers is a very important aspect that is reflected in improving rail safety.

\section{Research and results}

The paper [5] illustrates the process of transmitting the vibration from the train to a residential building through the conductivity of the soil, which has a significant impact on the comfort of people living nearby. The importance of getting to know this phenomenon is extremely important from the viewpoint of conducting further research aimed at building up better and better vibration insulators.

Novel technologies allow for better understand and counteract these phenomena. Shifting vibrations from the train through the ground is a complex, problematic, and dependent on many factors. It is divided into many stages and each one has its own characteristics. These phenomena are well described in eg articles [6-8].

The vibration and noise emitted by a rail vehicle affects people living in close proximity to passing traffic, which is particularly important for the safety of the entire transport process. In the article [9] concerning aspects of rail safety from the point of view of rail transport, the human factor and the current safety standards in Europe. It has been noted that the current procedures take into account the importance of the human factor to railways from a safety point of view, while further human intervention is needed in the process of creating better and better safety systems to prevent possible life-threatening and health-related traumas. There are also institutions dealing with rail safety issues. For example, TUV carries out a RAMS analysis of railway technology safety based on international standards for rail systems. The self-assessment of the safety management system and the railroad RAMS analyzes is, for example, the implementation of risk 
prevention measures and the ability to meet European safety and quality standards for rail transport [10]. To show how important from the point of view of rail transport is the human aspect shown in fig [11] the human factor on railways from the security and safety point of view in railway safety life-cycle.

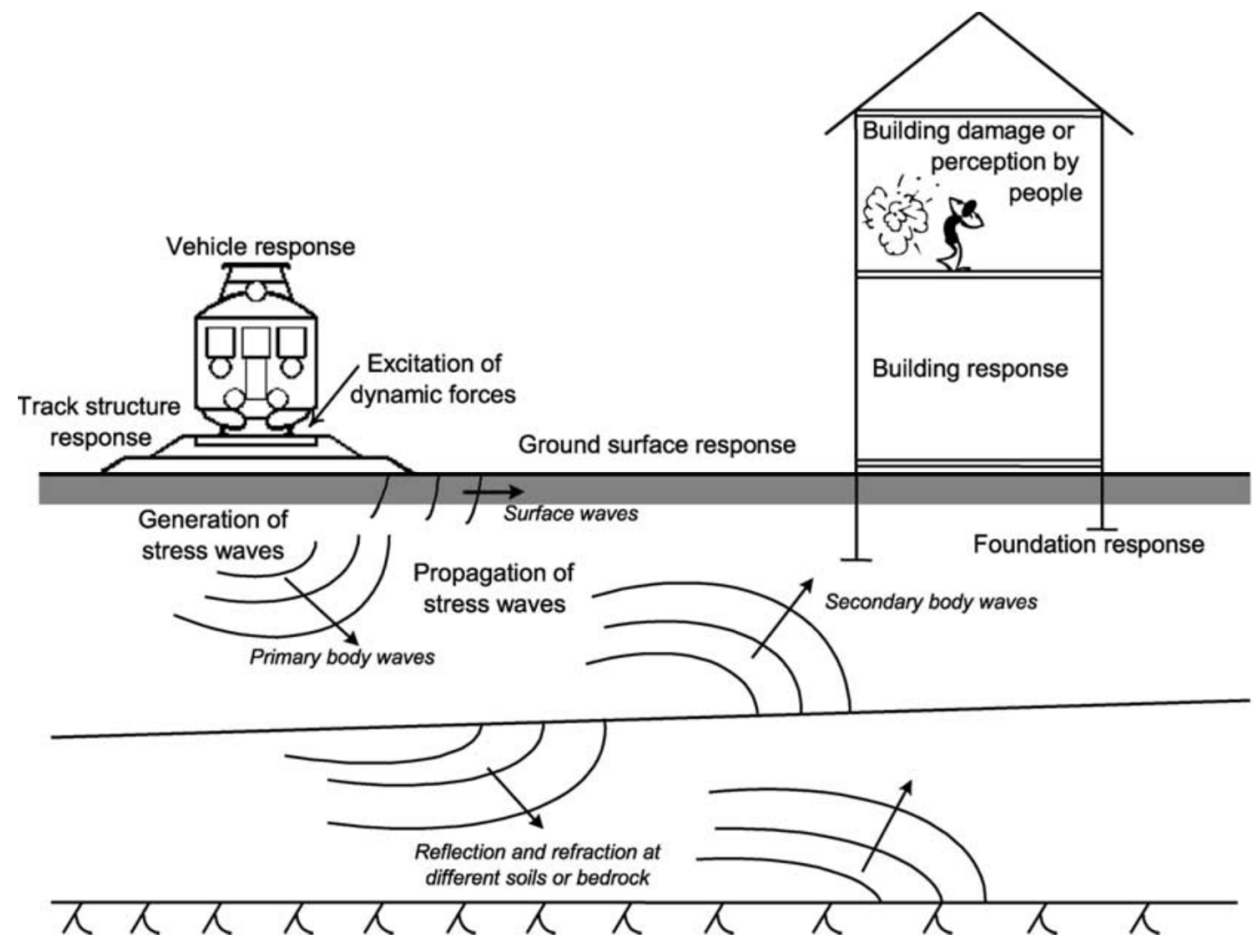

Fig. 1. The transmission process of train-indicated ground vibrations [5]

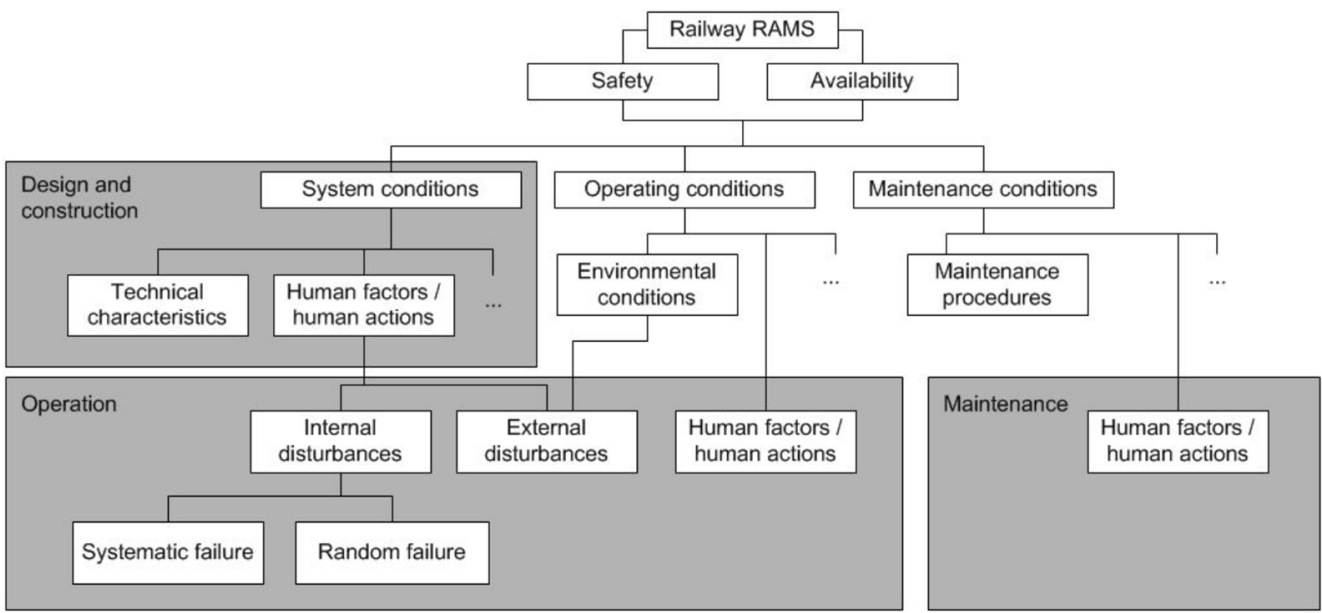

Fig. 2. Human factors in the railway system safety life-cycle [12]

Other companies providing services in the field of so- Intelligent technologies dealing with mechanics, electronics and vibroacoustics, based on intelligent materials, such as piezoelectric or magnetostrictive, perform vibration tests on rail vehicles (structural vibration measurements, spectral analysis of signals, propagation paths, or comfort factor calculations). For measurement of noise in rail vehicles, measurement and analysis of noise emitted by rail vehicles can be 
included in accordance with PN-EN ISO 3095: 2005 [13]. Measurement and analysis of noise inside rail vehicles is carried out in accordance with PN-EN ISO 3381: 2011 [11]. Accelerators, displacement sensors, sound level meters, laser vibrometers, electromagnetic actuators, and signal analyzer software are required to perform the tests.

Vulnerabilities and appropriate frequencies from a human health point of view can be represented by the Table 1 [14] and is reflected not only in rail transport.

Table 1. Vulnerabilities and appropriate frequencies from a human health

\begin{tabular}{|c|c|c|}
\hline Frequency of vibration & Example work & Biological reaction \\
\hline Up to $16 \mathrm{~Hz}$ & Impact tools & Disorder from the labyrinth \\
\hline $15-25 \mathrm{~Hz}$ & Miners, pitchers & Osteoarthritis \\
\hline $25-50 \mathrm{~Hz}$ & Pneumatic hammers & Osteoarthritis \\
\hline $35-100 \mathrm{~Hz}$ & Impact tools & Changes in the cardiovascular system \\
\hline $20-130 \mathrm{~Hz}$ & Grinder & Osteoarthritis \\
\hline $100-200 \mathrm{~Hz}$ & Impact tools & Vascular and nervous changes \\
\hline $40-50 \mathrm{~Hz}$ & Concreters & Vascular, nervous, vascular and "dental" \\
\hline $20-100 \mathrm{~Hz}$ & Machining of aluminum & Osteoarthritis \\
\hline
\end{tabular}

\section{Conclusions}

This article is a review of the knowledge about the dangers of vibration caused by passers-by which are becoming faster and heavier today. The ultimate purpose of this publication and the like is the increased interest in society of the risks associated with being in close proximity to railway lines. Thanks to the modernization of railway routes, increasingly more restrictive standards such as noise emission, rail transport is able to become a fully ecological means of transport with full regard for the word, and has not so far been treated in the light of tonne-kilometer costs or less degradation environment rather than road transport.

\section{References}

[1] Burdzik R., Nowak B. Identification of the vibration environment of railway infrastructure. Procedia Engineering, Vol. 187, 2017, p. 556-561.

[2] Młyńczak J., Burdzik R., Celiński I. Research on Dynamics of Shunting Locomotive During Movement on Marshalling Yard by Using Prototype of Remote Control Unit. Dynamical Systems: Theoretical and Experimental Analysis, Springer International Publishing, 2016, p. 279-292.

[3] Młyńczak J., Burdzik R., Celiński I. Remote monitoring of the train driver along with the locomotive motion dynamics in the course of shunting using mobile devices. Dynamical system Control and stability, 2015, p. 411-422.

[4] Siergiejczyk M., Paś J., Rosiński A. Issue of reliability-exploitation evaluation of electronic transport systems used in the railway environment with consideration of electromagnetic interference. IET Intelligent Transport Systems, Vol. 10, Issue 9, 2016, p. 587-593.

[5] Hall L. Simulations and analyses of train-induced ground vibrations in finite element models. Soil Dynamics and Earthquake Engineering, Vol. 23, Issue 5, 2003, p. 403-413.

[6] Auersch L. The Use and Validation of Measured, Theoretical, and Approximate Point-Load Solutions for the Prediction of Train-Induced Vibration in Homogeneous and Inhomogeneous Soils. Federal Institute for Materials Research and Testing, Berlin, 2013.

[7] Picoux B., Le Houedec D. Diagnosis and prediction of vibration from railway trains. Soil Dynamics and Earthquake Engineering, Vol. 25, 2005, p. 905-921.

[8] Degreande G., Schillemans L. Free Field Vibrations during the Passage of a Thalys High-Speed Train at Variable Speed. Belgium, 2001.

[9] Hamemerl M., Vanderhaegen F. Human factors in the railway system safety analysis process. 3rd Internationl Rail Human Factors Conference, 2009.

[10] https://www.tuv.com/poland/pl/analiza-rams.html.

[11] PN-EN ISO 3381:2011. 
[12] Anders E. Contribution to complex safety analysis of the railway system. Signal und Draht, Vol. 96, Issue 6, 2004, p. 6-10, (in Deutsch).

[13] PN-EN ISO 3095:2005.

[14] Grzegorczyk L., Walaszek M. Vibrations and Their Impact on the Human Body. Państwowy Zakład Wydaw, Lekarskich, Warszawa, 1972, (in Polish). 